In a recent study, we found that perineural invasion in needle prostatic biopsies significantly predicted prostatectomy stage $>$ pT2 in univariate $(p<0.01)$ but not in multivariate analysis $(p=0.38)$. In multivariate analysis preoperative PSA, Gleason grading and percentage of linear extent of cancer in $\mathrm{mm}$ in the needle biopsy were the significant variables predictive of $>$ pT2.

We agree with Loeb's et al. conclusion that nerve-sparing surgery does not adversely affect biochemical progression even among men with perineural invasion.

\title{
References
}

1. Bastacky SI, Walsh PC, Epstein JI: Relationship between perineural tumor invasion on needle biopsy and radical prostatectomy capsular penetration in clinical stage B adenocarcinoma of the prostate. Am J Surg Pathol. 1993; 17: 336-41.

2. Egan AJM, Bostwick DG: Prediction of extraprostatic extension of prostate cancer based on needle biopsy findings: Perineural invasion lacks significance on multivariate analysis. Am J Surg Pathol. 1997; 21: 1496-500.

Dr. Athanase Billis

Full-Professor of Pathology

State University of Campinas, Unicamp

Campinas, São Paulo, Brazil

E-mail: athanase@fcm.unicamp.br

\section{A pathological reassessment of organ-confined, Gleason score 6 prostatic adenocarcinomas that progress after radical prostatectomy}

Miyamoto H, Hernandez DJ, Epstein JI

The Department of Pathology, The Johns Hopkins University School of Medicine, Baltimore, MD, USA

Hum Pathol. 2009 Aug 13. [Epub ahead of print]

Prior studies of radical prostatectomies have reported a small percentage of men with biochemical progression after radical prostatectomy showing organ-confined, Gleason score 6 . One might predict that this should virtually never occur. We identified 2551 (1983-2005) radical prostatectomies coded by the urologists at our institution as pathologically organ-confined, Gleason score 6 cancer with more than 1 year of follow-up. We re-examined histopathogically the serially sectioned and completely embedded radical prostatectomy specimens of 38 men who developed biochemical recurrence defined as a single prostate-specific antigen level of $0.2 \mathrm{ng} / \mathrm{mL}$ or greater. In 27 (71\%) of 38 of cases, pathology re-review showed higher grade or stage than coded by the urologists. These included 10 cases of organ-confined with Gleason pattern 4 as either the primary or secondary pattern; 9 cases of organ-confined, Gleason score 6 with tertiary pattern 4 (in 4 cases, tertiary pattern 4 was described in the initial pathology report); 5 cases of Gleason score 7 plus extraprostatic extension; 1 case of Gleason score 6 with focal extraprostatic extension; and 2 cases with positive margins due to intraprostatic incision (listed in the initial pathology report). The remaining 11 cases were true organ-confined, Gleason score 6 tumors, but none of the patients developed systemic disease. Most prior reports of organ-confined, Gleason score 6 with progression are undergraded (upgrading with revision of Gleason system), understaged (difficulty recognizing focal extraprostatic extension), or suffer from situations with ambiguous staging (intraprostatic incision) or grading (tertiary pattern 4 or $2+4=6$ ). Even for the rare true organ-confined, Gleason score 6 (no pattern 4 ) tumor with supposed biochemical progression, some may be false-positive progression based on low post-radical prostatectomy prostate-specific antigen levels and minute tumors that seem highly improbable to progress. With accurate pathologic evaluation, men with organ-confined, Gleason score 6 (no pattern 4) prostate cancer can be told that their risk of progression is very rare $(0.4 \%)$. 


\section{Editorial Comment}

This study may be intriguing for the urologist. From a total of 38 patients reported as having organconfined cancer who developed biochemical recurrence defined as a single prostate-specific antigen level of $0.2 \mathrm{ng} / \mathrm{mL}$ or greater, pathology re-review showed that only 11 cases were true organ-confined. How does it happen?

Pathologists use strict criteria for diagnosis however there are many interpretative dilemmas. Experience and specialization are important considerations. One example is the Gleason grading reproducibility that can be categorized as intraobserver or interobserver. Exact interobserver agreement may vary from $36 \%$ to $81 \%$; interobserver agreement +1 score unit from 69\% to 86\%; and, the kappa values from 0.13 to 0.78 (slight to substantial agreement) (1).

Another example refers to criteria for extraprostatic extension. In the posterior, posterolateral and lateral aspects of the prostate gland, tumor admixed with periprostatic fat is the most recognized manifestation of extraprostatic extension. However, tumor in fat is not synonymous with extraprostatic extension and pathologists should be aware that intraprostatic adipocytes will be found in up to $5 \%$ of radical specimens. Another more common problem relates to the desmoplastic reaction that sometimes occurs in a tumor invading the adipose tissue replacing it. In this circumstance is difficult to evaluate extraprostatic extension. A bulging contour beyond the normal contour of the gland indicates extraprostatic extension (2). However, this finding may also be interpretative.

\section{References}

1. Amin MB, Grignon DJ, Humphrey PA, Srigley JR: Gleason Grading of Prostate Cancer. A Contemporary Approach. Philadelphia, Lippincott Williams \& Wilkins. 2004.

2. Epstein JI, Amin M, Boccon-Gibod L, Egevad L, Humphrey PA, Mikuz G, et al.: Prognostic factors and reporting of prostate carcinoma in radical prostatectomy and pelvic lymphadenectomy specimens. Scand J Urol Nephrol. 2005; 39 (Suppl 216): 34-63.

Dr. Athanase Billis Full-Professor of Pathology State University of Campinas, Unicamp

Campinas, São Paulo, Brazil E-mail:athanase@fcm.unicamp.br

\section{BASIC AND TRANSLATIONAL UROLOGY}

\section{Urodynamic and immunohistochemical evaluation of intravesical botulinum toxin A delivery} using liposomes

Chuang YC, Tyagi P, Huang CC, Yoshimura N, Wu M, Kaufman J, Chancellor MB

Department of Urology, Chang Gung Memorial Hospital, Kaohsiung Medical Center, Chang Gung University College of Medicine, Kaohsiung, Taiwan, Republic of China

J Urol. 2009; 182: 786-92

Purpose: Botulinum toxin A (Allergan, Irvine, California) is a high molecular weight neurotoxin used to treat hypersensitive bladder by direct injection to pass the urothelial barrier. We investigated the feasibility of intravesical botulinum toxin A delivery using liposomes (Lipella Pharmaceuticals, Pittsburgh, Pennsylvania), which 